Saudi Journal of Medical and Pharmaceutical Sciences

Abbreviated Key Title: Saudi J Med Pharm Sci ISSN 2413-4929 (Print) |ISSN 2413-4910 (Online) Scholars Middle East Publishers, Dubai, United Arab Emirates Journal homepage: https://saudijournals.com/sjmps

\title{
Spectrum of Rheumatology Disorders among Patients Presenting With Hypothyroidism
}

Dr. Akintayo Segun Oguntona. MBChB, FWACP ${ }^{1 *}$, Dr. Ricardo Morasen Cuevas Jose ${ }^{2}$, Dr. Mazwa Hussein ${ }^{2}$, Dr. Olatunde Odusan MBBS, FMCP ${ }^{1}$, Dr. Ayotunde Ale MBBS, FMCP, FACE ${ }^{1}$

${ }^{1}$ Lecturer/Consultant Physician, Department of Medicine, Olabisi Onabanjo University/ Teaching Hospital, Hospital Road, Sagamu, Nigeria

${ }^{2}$ Rheumatology Specialist, King Abdul-Azeez Specialist Hospital, 26521 Qurwa، Taif 26521, Saudi Arabia

DOI: $10.36348 /$ sjmps.2020.v06i01.012

| Received: 13.01 .2020 | Accepted: 20.01.2020 | Published: 23.01.2020

*Corresponding author: Akintayo Segun Oguntona

\section{Abstract}

Background: Hypothyroidism is one of the major endocrine diseases involving various organs including musculoskeletal systems. Musculoskeletal involvement has led to varying degree of morbidity. The mechanism of musculoskeletal involvement is probably auto-immune related. Methods: This was a prospective study of the patients with diagnosis of hypothyroidism referred from the endocrine clinic with various musculoskeletal complaints. The duration of the study was one year (July 2018-June 2019). All the patients with hypothyroidism with musculoskeletal complaints were included. Excluded were patients with other endocrine and infectious diseases. Results: Eight hundred and fourty rheumatology patients were seen over the study period. Females constituted $72.6 \%$. One hundred and twenty-six hypothyroid patients were seen during the period comprising $112(88.9 \%$ females and $14(11.1 \%)$ males. The mean age of patients was $44 \pm 8$ years. Most patients $(90.3 \%)$ presented at the rheumatology clinic after the third year of diagnosis of hypothyroidism. Generalized body pain was the leading non-articular disease, while myopathy ranked first among muscle and articular disorders. Normocytic normochromic anaemia, abnormal lipid profile and elevated creatine phosphokinase (CPK) enzyme were the predominant laboratory abnormalities. Conclusion: Due to overlapping of symptoms of hypothyroidism over those of systemic auto-immune diseases, it is therefore important to perform thyroid function test in patients presenting with musculoskeletal complaints.

Keywords: Hypothyroidism, endocrine diseases, Musculoskeletal involvement.

Copyright @ 2020: This is an open-access article distributed under the terms of the Creative Commons Attribution license which permits unrestricted use, distribution, and reproduction in any medium for non-commercial use (NonCommercial, or CC-BY-NC) provided the original author and source are credited.

\section{INTRODUCTION}

Musculoskeletal system involvement is a common finding in hypothyroidism. The association between rheumatic diseases and thyroid disorders has been known a long time ${ }^{1}$. Sir William Gull in 1873 described the association of neck stiffness and joint pain in hypothyroidism and other early British reports were described by Doyle ${ }^{2}$. In 1883, Coxwell ${ }^{3}$ described myopathy in a case of juvenile myxoedema in a 13-year old girl.

Autoimmunity has been proposed as the probable mechanism rather than the direct effect of thyroid hormone [4]. Suggested hypotheses are the probable role of autoantibodies present in autoimmune thyroiditis and overlap between autoimmune thyroiditis [4].
Prevalence of autoimmune thyroid diseases in patients with connective tissue disorders has been found to be on the increase and also the frequency of rheumatic diseases is reported to be higher in patients with autoimmune thyroid diseases, suggesting a common mechanism for the disease pathogenesis [5].

The spectrum of musculoskeletal involvement in hypothyroidism varies from soft tissue to arthropathies of small and large joints, muscle weakness, osteoarthritis, inflammatory arthritis, fibromyalgia, polymyalgia rheumatica, secondary Sjogren's syndrome, mixed connective tissue disease and rarely vasculitis [6].

Thyroxin treatment and disease modifying anti-rheumatic medications in patients with combined rheumatoid arthritis and hypothyroidism have been found to remarkably improve the disease activity in rheumatoid arthritis [7]. 
Prevalence of hypothyroidism was reported to be higher in lupus patients when compared with the general population and there was a higher frequency of thyroid auto-antibodies [8]. Hypothesis has suggested that the overlapping clinical features seen in fibromyalgia and hypothyroidism may be as a result of thyroid hormone resistance [4].

The objective of this study was to report the different rheumatic manifestations in patients suffering from hypothyroidism.

\section{Patients And Methods}

This was a prospective study of the patients with diagnosis of hypothyroidism referred from the endocrine clinic for different musculoskeletal complaints. The study was carried out at the rheumatology and endocrine outpatient clinics of two tertiary institutions over one year, from July 2018 to June 2019. Exclusion criteria from the study were patients with diabetes mellitus, retroviral infection, hepatitis $\mathrm{B}$ and $\mathrm{C}$ infection, pre-existing neuromuscular disorders and patients on prolonged use of corticosteroid. Patients with chronic liver and renal diseases were also excluded.

Demographic characteristics of the patients were taken, body mass index (weight in $\mathrm{kg}$ divided by the patient's height in $\mathrm{m}^{2}$ ) equal or greater than 25 was considered abnormal. Waist circumference was defined according to the International Diabetes Federation (IDF). Waist circumference equal or greater than $94 \mathrm{~cm}$ was considered abnormal for men and equal or greater than $80 \mathrm{~cm}$ for women.

Clinical examination was carried out with emphasis on the musculoskeletal presentation. Investigations were requested as necessary and tailored to the diagnosis of each condition. Some of the investigations requested for were full blood count, erythrocyte sedimentation rate (ESR), C- reactive protein (CRP), anti-nuclear antibody (ANA), rheumatoid factor $(\mathrm{RF})$ and anti-citrullinated peptide.

Other investigations were creatinine phosphokinase (CPK), alanine transferase (ALT), aspartate transferase (AST), X-rays and the ultrasound of the affected joints. Nerve conduction velocity study (NCV), joint fluid analysis and muscle biopsy were requested as indicated. Lipid profile, and anti-thyroid peroxides (anti-TPO) were already done from the referring endocrine clinics. At the time of consultation at the rheumatology clinic, all the patients were already placed on thyroxin replacement medication.

\section{Statistical Analyses}

Data were collated, tabulated, and statistically analyzed. Analysis of data was done using statistical program for social science (SPSS) version 20. Quantitative variables were described as mean, standard deviation and range while qualitative variables were described as number and percentage.

\section{RESUlTS}

The total number of rheumatology patients seen over a period of 1 year (July 2018-June 2019) was 840.There were 610 females $(72.6 \%)$ and 230 males $(27.4 \%)$. A total of 126 hypothyroid patients were seen during the study period. There were $112(88.9 \%)$ females and $14(11.1 \%)$ males, with a female to male ration of $8: 1$. The age range was $22-65$ years with a mean age of $44 \pm 8$ years. Four percent of the population was underweight, $48 \%$ had normal weight, $40 \%$ were overweight and $34 \%$ were obese. Table-1 shows the socio- demographic characteristics of the patients.

Most patients $(90.3 \%)$ presented to the rheumatology clinic after the third year of diagnosis of hypothyroidism, while $7.5 \%$ presented after one year of duration of hypothyroidism. Few patients (2.2\%) however presented after 10 years of diagnosis of hypothyroidism.

Leading among the non-articular diagnosis were generalized body pain (34.9\%), fibromyalgia (20.9\%) and carpal tunnel syndrome (13.9\%). Fibromyalgia was mainly seen among women. Trigger finger and epicondylitis were the least among the non articular presentations. Figure-1 shows the non-articular presentations. Predominant among the muscle and articular disorders were myopathy (27.1\%), osteoarthritis (20.8\%) and non erosive arthritis (14.5\%). Only one case of SLE was seen in association with hypothyroidism. Table- 2 shows the muscle and articular manifestatons.

Laboratory investigations revealed $48.2 \%$ with normocytic normochromic anemia, elevated triglyceride and cholesterol in $56.4 \%$, elevated creatine phophokinase (CPK) enzyme in $30.8 \%$ (4 out of 13 patients with myopathy), significant titre of rheumatoid factor in all the three patients with rheumatoid arthritis while two $(66.7 \%)$ had positive anti-citrullinated peptide. Antinuclear antibody (ANA) was significantly positive with speckle pattern in the patient with SLE. The patients with polyarticular rheumatoid-like presentation were sero-negative and no-erosion was detected on plain radiograph. 
Table-1: Socio-demographic characteristics of the patients with hypothyroidism

\begin{tabular}{|l|l|}
\hline Parameter & Result \\
\hline Females & $112(88.9 \%)$ \\
\hline Male & $14(11.1 \%)$ \\
\hline Age range & $22-65$ years \\
\hline Mean age & $44 \pm 8$ \\
\hline Duration of disease & $1^{1 / 2}-10$ years \\
\hline Mean duration of disease & $4.9 \pm 4$ years \\
\hline Underweight & 04 \\
\hline Normal weight & 48 \\
\hline Over weight & 40 \\
\hline Obese & 34 \\
\hline
\end{tabular}

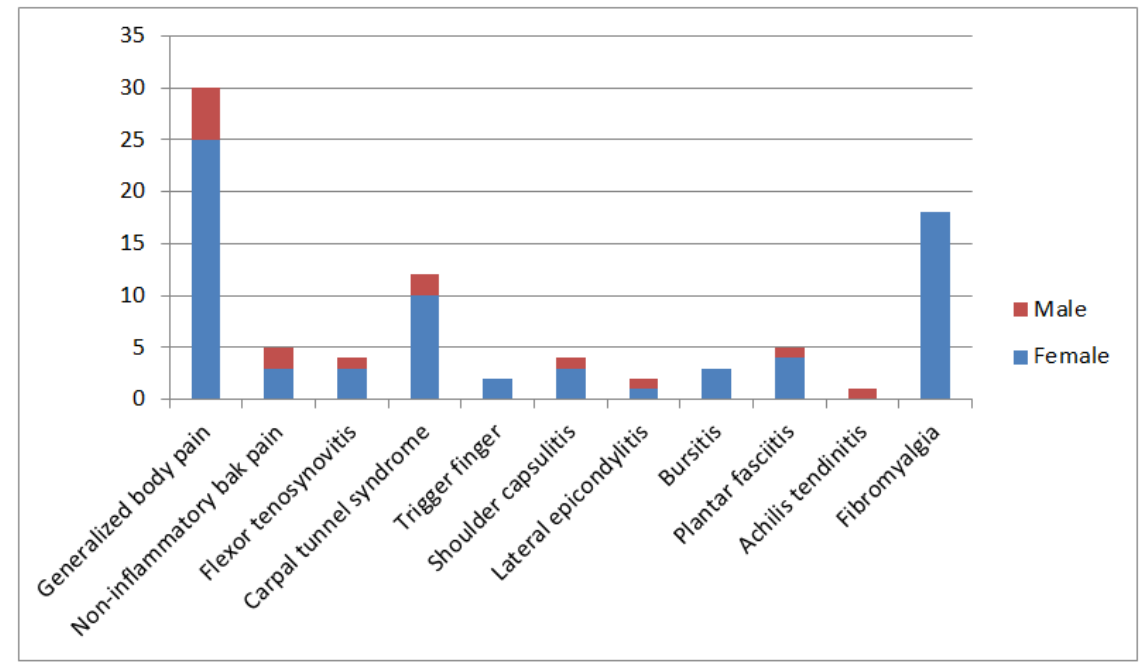

Fig-1: Showing non-articular disorders encountered in patients with hypothyroidism

Table-2: Showing muscle and articular problems seen in patients with hypothyroidism

\begin{tabular}{|l|l|l|l|}
\hline Muscle and articular problem & $\begin{array}{l}\text { Female (\%) } \\
\mathbf{n = 3 4}\end{array}$ & $\begin{array}{l}\text { Male (\%) } \\
\mathbf{n = 1 4}\end{array}$ & $\begin{array}{l}\text { Total (\%) } \\
\mathbf{n = 4 8}\end{array}$ \\
\hline Osteoarthritis & $07(70)$ & $03(30)$ & $10(20.8)$ \\
\hline Myopathy & $10(76.9)$ & $03(23.1)$ & $13(27.1)$ \\
\hline Non erosive arthritis & $05(71.4)$ & $2(28.6)$ & $07(14.5)$ \\
\hline Rheumatoid arthritis & $02(66.7)$ & $01(33.3)$ & $03(6.3)$ \\
\hline Systemic lupus erythematosus & $01(100)$ & - & $01(2.1)$ \\
\hline Mixed connective tissue disease & $01(100)$ & - & $01(2.1)$ \\
\hline Scleroderma & $02(100)$ & - & $02(4.2)$ \\
\hline Gouty arthritis & $01(25)$ & $03(75)$ & $04(8.3)$ \\
\hline Undifferentiated connective tissue disease & $01(33.3)$ & $02(66.7)$ & $03(6.3)$ \\
\hline Polymyalgia rheumatica & $04(100)$ & - & $04(8.3)$ \\
\hline
\end{tabular}

\section{DISCUSSION}

The close relationship between hypothyroidism and rheumatic diseases has long existed. Apart from the fact that the clinical manifestations of hypothyroidism emulate those of rheumatic diseases, it also frequently presents with primary rheumatologic complaints and in fact rheumatologic manifestations may occasionally be the clue to the diagnosis of hypothyroidism [9].

In 1970, Bland and Frymoyer [10] described rheumatic findings in 38 patients with hypothyroidism.
Eleven of the patients had rheumatology findings. Joint involvement was concurrent with onset of hypothyroidism in 6, hypothyroidism preceded the arthropathy in 3 and arthropathy appeared first in 2 patients.

In adults, there are diverse musculoskeletal manifestations of hypothyroidism. These include muscle weakness, arthralgias, arthritis, myalgias with or without elevations in muscle enzymes, carpal tunnel syndrome, osteoarthritis, and crystal induced arthritis. Arthropathy associated with hypothyroidism commonly affects the knees, metatarsal phalangeal (MTP) joints, 
wrists, metacarpophalangeal (MCP) joints, and the proximal interphalangeal (PIP) joints [11].

Various combinations of musculo-skeletal problems were observed in the cohort of hypothyroid patients seen in this study. Similar finding was reported in the study done in India by Pillai et al., [12]. Musculo-skeletal complaints were noted among people with normal thyroxin level and those with sub-normal level in this study. People with sub-normal level of thyroxine however presented more with muscular and articular problems than those with normal thyroxin level, though, not statistically significant $(\mathrm{p}=0.08)$.

Diffuse body pain involving soft tissues and joints was common to all our patients. It is the leading non-articular problem encountered in $34.9 \%$ of our patients. Occasionally, the pain was very severe, and affected different parts of the body at different times. Majority of the patients $(84 \%)$ in this group still suffered from episodes of diffuse body pain even months after the commencement of thyroxin. Few of these patients presented with muscle stiffness. The stiffness was frequently most pronounced in the early morning and usually lasted 15 to 30 minutes. This presentation could easily be confused with polymyalgia rheumatica- like iIIness. The diagnosis of hypothyroidism should therefore be considered in patients who have a polymyalgia rheumatica- like picture and a normal or only slightly elevated erythrocyte sedimentation rate.

Eighteen females were diagnosed with fibromyalgia in this study. Hypothyroid patients may present with a fibromyalgia -like picture. These presentations may be prominent in patients who have muscular symptoms as a component of a hypothyroid state. Hypothyroidism may be difficult to distinguish from fibromyalgia, because patients with hypothyroidism often complain of generalized aches, fatigue, and interrupted sleep. In patients suspected clinically to have hypothyroidism, thyroid function studies such as serum thyroid-stimulating hormone (TSH), can be used to establish the presence of thyroid disease [13]. Thyroid function is normal in patients with fibromyalgia in the absence of coexisting thyroid disease. Thyroid autoantibodies are however common in patients with fibromyalgia [13]. Earlier research had reported that about $22 \%$ cases of fibromyalgia had blunted TSH response with $7 \%$ patients having subclinical hypothyroidism [14].

Carpal tunnel syndrome was diagnosed by electromyography in $13.9 \%$ of our patients. Carpal tunnel syndrome was reported by various studies to be associated with hypothyroidism [15, 16]. Proposed aetiological mechanisms for carpal tunnel syndrome include; direct pressure on the nerve from an oedematous transverse carpal ligament, flexor tenosynovitis, infiltration of the perineurium and endoneurium with accumulation of glycosaminoglycans with resultant neuronal metabolic dysfunction. Most studies have however revealed a rapid resolution of symptoms when thyroid hormone replacement is commenced [17].

Seven $(14.5 \%)$ of our patients presented with a non-erosive arthritis. Hypothyroidism often presents with a characteristic symmetrical arthropathy involving stiffness of the joints of the hands; wrist, metacarpophalangeal and proximal interphalangeal joints and knees. Morning stiffness usually lasts less than 30 minutes and only a minority has signs of acute inflammation [18]. These clinical features sometimes lead to an initial erroneous diagnosis of inflammatory arthritis.

There were $27.1 \%$ of our patients with muscular pain and weakness. Serum creatine kinase (CK) was elevated in $30.8 \%$ (4 out of 13) of these people. Electromyograms revealed myopathic potentials, smaller and shorter individual action potentials, an increased proportion of poIyphasic potentials and increased insertional activity in $38.5 \%$. Fibrillations were less common findings.

Neuromuscular symptoms are common in hypothyroidism and can occur any time during the course of the disease [19]. Explanations for the effect of thyroid hormone on muscle include delayed contraction and relaxation, alteration in myosin heavy chain gene forms, and impaired glycogenesis [19]. The symptoms include weakness, cramping, myalgias, diminished reflexes and myoedema. Weakness is the most common phenomena. Creatine kinase (CK) may or may not be elevated. Muscle Cramp can be severe, and myalgias worse after exertion [19].

The articular manifestations were better in all the groups when non-steroidal anti-inflammatory and disease modifying drugs were commenced. Better improvement was however noticed in the group with improved thyroid hormone level. Various research works have documented this fact [20, 21].

The relationship between hypothyroidism and rheumatic diseases is significant. Since the musculoskeletal presentations of hypothyroidism can predate the clinical manifestations, a high index of suspicion must be entertained by the treating physician. It is also essential to consider thyroid function test in various autoimmune rheumatic conditions. It is therefore necessary that the Rheumatologists and the Endocrinologists should work together in order to alleviate the morbidity associated with the disease. 


\section{REFERENCES}

1. Anwar, S., \& Gibofsky, A. (2010). Musculoskeletal manifestations of thyroid disease. Rheum Dis Clin North Am. 36(4):637-646.

2. Doyle, L. (1991). Myxoedema: some early reports and contributions by British authors. Journal $R$ Soc Med. 84:103-106

3. Coxwell, C. F. (1883). Trans Clin Soc London. 16:75-79.

4. Punzi, L., \& Betterle, C. (2004). Chronic autoimmune thyroiditis and rheumatic manifestations. Joint Bone Spine. 71(4):275-283.

5. Arnaout, M. A., Nasrallah, N. S., \& Ei-khateeb, M. S. (1994). Prevalence of abnormal thyroid function test in connective tissue diseases. Journal of Rheumatology. 23(3):128-132.

6. Golding, D. N. (1993). Rheumatism and the thyroid. Journal of the Royal Society of Medicine, 86(3), 130-132.

7. Delamere, J. P., Scott, D. L., \& Felix-Davies, D. D. (1982). Thyroid dysfunction and rheumatic diseases. Journal R Soc Med. 75(2):102-106.

8. Appenzeller, S., Pallone, A. T., Natalin, R. A., Costallat, L. T. (2009). The thyroid lupus relationship; prevalence of thyroid dysfunction in systemic lupus erythematosus. Journal Clin Rheumatol. 15(3):117-119.

9. Shiroky, J., Cohen, M., Ballachey, M., \& Neville, C. (1993). Thyroid dysfunction in rheumatoid arthritis; a controlled prospective survey. Ann Rheum Dis, 1993; 52:454-456.

10. Bland, J. H., \& Frymoyer, J. W. (1970). Rheumatic syndromes of myxedema. $N$ Engl $J$ Med. 282(21):1171-1174

11. Lazúrová, I., Benhatchi, K., Rovenský, J., Kozáková, D., Wagnerová, H., Tajtáková, M., ... \& Macejova, Z. (2009). Autoimmune thyroid disease and autoimmune rheumatic disorders. Annals of the New York Academy of Sciences, 1173(1), 211-216.

12. Pillai, M. G., Kumaravel, V., Nisha, B., Hareesh, C., Unnikrishnan, A. G., Nair, V., ... \& Kumar, H.
(2009). Prevalence of musculoskeletal manifestations in thyroid disease. Thyroid Research and Practice, 6(1), 12-16.

13. Bazzichi, L., Rossi, A., Zirafa, C., Monzani, F., Tognini, S., Dardano, A., ... \& De Feo, F. (2012). Thyroid autoimmunity may represent a predisposition for the development of fibromyalgia?. Rheumatology international, 32(2), 335-341.

14. Suk, J. H., Lee, J. H., \& Kim, J. M. (2012). Association between thyroid autoimmunity and fibromyalgia. Exp Clin Endocrinol Diabetes. 120:401-404.

15. De Rijk, M. C., Vermeij, F. H., Suntjens, M., \& van Doorn, P. A. (2007). Does a carpal tunnel syndrome predict an underlying disease? Journal Neurol Neurosurg Psychiatr. 78(6):635-637.

16. Katz, J. N., Larson, M. G., Sabra, A., Krarup, C., Stirrat, C. R., Sethi, R., ... \& Liang, M. H. (1990). The carpal tunnel syndrome: diagnostic utility of the history and physical examination findings. Annals of Internal Medicine, 112(5), 321-327.

17. Shiri, R. (2014). Hypothyroidism and carpal tunnel syndrome: a meta analysis. Muscle Nerve. 50:879-883.

18. Mehtap, C., Nehir, S., Nilufer, B., \& Mustafa, K. B. (2003). Musculoskeletal manifestations in patients with thyroid disease. Clinical Endocrinology. 59:162-167.

19. Madhu, S. V., Jain, R., Kant, S., Prakash, V., \& Kumar, V. (2010). Myopathy presenting as a sole manifestation of hypothyroidism. Journal Assoc Physicians India. 58:569-570.

20. Scott, K. R., Simmons, Z., Boyer, P. J. (2002). Hypothyroid myopathy with a strikingly elevated serum creatine kinase level. Muscle Nerve. 26(1):141-144.

21. Ciompi, M. L., Zuccotti, M., Bazzichi, L., \& Puccetti, L. (1994). Polymyositis-like syndrome in hypothyroidism: report of two cases. Thyroidology. 6(1):33-36. 